\title{
TRANSATRIAL AND TRANSMITRAL APPROACH FOR LEFT VENTRICULAR MYECTOMY AND MITRAL VALVE PLICATION FOR DIFFUSE-TYPE HYPERTROPHIC OBSTRUCTIVE CARDIOMYOPATHY: A NOVEL APPROACH
}

\author{
Hikaru Matsuda, MD, ${ }^{a}$ Fumikazu Nomura, MD, ${ }^{a}$ Keishi Kadoba, MD, ${ }^{a}$ Kazuhiro Taniguchi, MD, \\ Hiroshi Imagawa, MD, ${ }^{a}$ Koji Kagisaki, MD, ${ }^{a}$ and Tetsuya Sano, MD, ${ }^{b}$ Osaka, Japan
}

In the management of patients with hypertrophic obstructive cardiomyopathy (HOCM), surgical intervention has been widely accepted as a reliable treatment for those with moderate to severe muscular obstruction and an unsatisfactory response to medical therapy. ${ }^{1}$ Because of recent advances in understanding the anatomic and physiologic background of subaortic and intraventricular obstruction, the role and method of surgical intervention has progressively changed. In addition to myotomy and myectomy, introduced by Morrow ${ }^{2}$ in 1978 , mitral valve repair and anterior mitral leaflet plication ${ }^{3}$ have been reported to be efficient alternatives to mitral valve replacement.

At present, the transaortic approach is a standard technique for subaortic myectomy unless the aortic valve ring is hypoplastic. However, the transaortic approach has some disadvantages, such as limited operative view, risk of creating late aortic valve insufficiency, and difficulties in approaching the midportion or more distal portion of the left ventricle $(\mathrm{LV})$. Also, in case of mitral valve insufficiency, mitral annuloplasty may be difficult through the aortic valve, although this approach can provide an opportunity for mitral valve plication. In children, this technique may give an inadequate operative view of both the subaortic obstruction and the mitral valve leaflet. In this article, we propose a novel approach and technique for LV myectomy with mitral valve remodeling including mitral annuloplasty and extended myectomy, all done through the left atrium and mitral anulus during temporary detachment of the anterior mitral valve.

Case report. An 11-year-old boy had had a diffuse type of HOCM, ${ }^{4}$ as well as von Recklinghausen's disease, since 3 weeks after birth. Serial echocardiograms revealed systolic anterior movement of the mitral valve owing to abnormal attachment of the anterior chordae and mitral regurgitation (mild to moderate) without leaflet prolapse but with elongation of the anterior mitral leaflet. The fact that there was almost no cavity at systole from the level of the papillary muscle to the $L V$ apex correlated well with

From the First Department of Surgery ${ }^{a}$ and the Department of Pediatrics, ${ }^{\text {b }}$ Osaka University Medical School, Osaka, Japan.

Received for publication Dec. 14, 1995; accepted for publication Jan. 5, 1996.

Address for reprints: Hikaru Matsuda, MD, First Department of Surgery, Osaka University Medical School, 2-2 Yamadaoka, Suita, 565 Osaka, Japan.

J Thorac Cardiovasc Surg 1996;112:195-6

Copyright (C) 1996 by Mosby-Year Book, Inc.

$0022-5223 / 96 \$ 5.00+0 \quad \mathbf{1 2 / 5 4 / 7 1 6 2 3}$

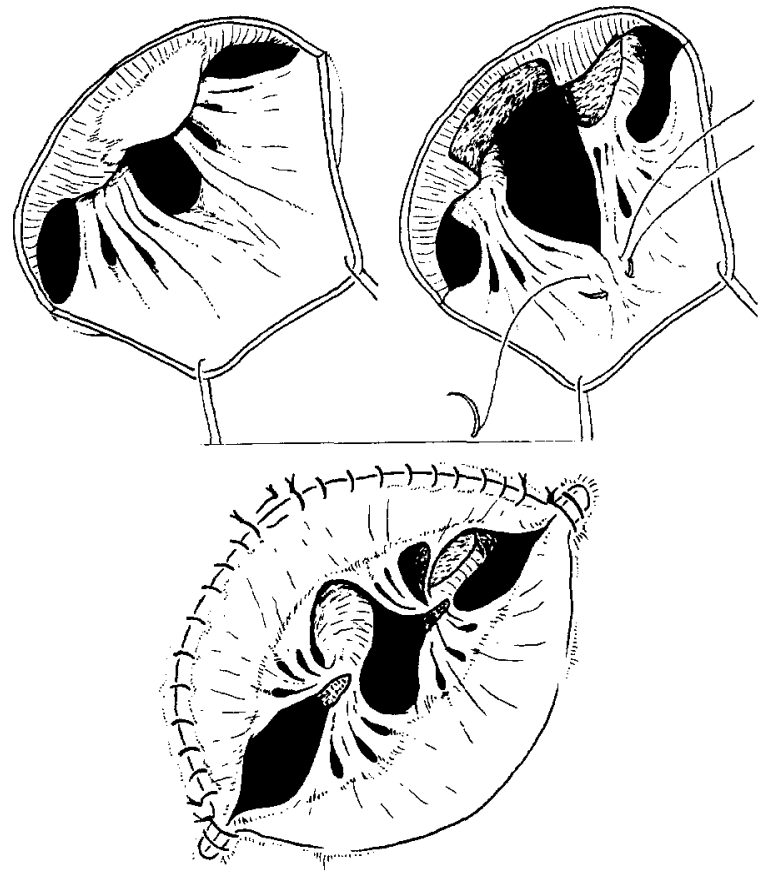

Fig. 1. Schema of operation. Temporary detachment of anterior mitral anulus (left upper panel). Mitral valve repair (right upper panel). Myectomy of papillary muscle and septal hypertrophied muscle (right upper and lower).

the surgical findings-a thickened, elongated anterior mitral leaflet and relatively modest septal hypertrophy. Myectomy to the papillary muscle and septal hypertrophied muscle close to the apex was performed through the left atrium and mitral anulus with temporary detachment of the anterior mitral leaflet. This resulted in a peak LV apex-aorta gradient of $40 \mathrm{~mm} \mathrm{Hg}$ at rest. The mitral valve was repaired by plication of the anterior mitral leaflet, anterior papillotomy, and commissural annuloplasty with reattachment of the detached anterior mitral anulus (Fig. 1).

Postpump transesophageal echocardiography revealed trivial mitral regurgitation and no systolic anterior movement of the anterior leaflet, which could increase the intraventricular space at the level of the papillary muscle. Cardiac catheterization, performed 1 month after the operation, revealed no mitral regurgitation and no $\mathrm{LV}$ outflow tract obstruction, but a $57 \mathrm{~mm} \mathrm{Hg}$ gradient across 
the LV apex to the LV outflow tract. The patient had an uneventful recovery and was discharged in good condition, receiving $60 \mathrm{mg}$ of propranolol and $120 \mathrm{mg}$ of nifedipine daily.

Comment. A transatrial approach for resection of subaortic muscular obstruction was first reported by Lillehei and Levy $^{5}$ in 1963. In their report, the approach was through a left thoracotomy and left atriotomy under induced ventricular fibrillation. In this report, we introduced this technique through the standard median sternotomy and cardioplegic arrest. Temporary detachment of the anterior mitral leaflet through the left atrium facilitated a wide view of the subaortic and the lower portion of the septum. This method also provides a direct approach to the anterior mitral leaflet, chordae, and papillary muscle. In our case the plication of the anterior mitral leaflet was easily performed, and myectomy and myotomy to the papillary muscle and hypertrophied muscle mass close to the apex were easily done as well. Furthermore, mitral annuloplasty could be performed during and after reattachment of the anulus. There was no risk of structural injuries to either the mitral or aortic valve or anulus.

We propose that subvalvular myectomy combined with mitral valve remodeling can be done through this approach. The mitral interventions consist of plication of the leaflet and additional myectomy to the papillary muscle and adjacent apical muscle mass. These procedures provide relief from systolic anterior motion, which has a major role in LV outflow tract obstruction, and help to increase the intraventricular space at the level of papillary muscle and apex. In our case, a postoperative angiogram showed complete disappearance of systolic motion of the mitral component and a significant decrease in the pres- sure gradient between the midportion of the LV and the subaortic route. However, the volume of the ventricle itself continues to be restricted, possibly because the muscle resection was suboptimal. Future growth of the LV cavity can be expected after reduction of the outflow obstruction. Of course, this hypothesis must be validated by future assessment of the patient.

This is a single case report. The procedure requires further evaluation with more patients and long-term assessment. However, we believe that this technique may be useful for those with a small aortic anulus and for infants and children. Importantly, this approach can provide an adequate operative view for those with diffuse-type HOCM with various degrees of pathologic changes of the mitral valve, giving an opportunity to perform combined procedures suitable for the variations of the anatomic and physiologic derangement.

\section{REFERENCES}

1. McIntosh, GL, Maron BJ. Current operative treatment of obstructive hypertrophic cardiomyopathy. Circulation 1988; 78:487.

2. Morrow AG. Hypertrophic subaortic stenosis: operative methods used to relieve left ventricular outflow obstruction. J Thorac Cardiovase Surg 1978;76:423-30.

3. Cooley DA, Wukasch DC, Leachman RD. Mitral valve replacement for idiopathic hypertrophic subaortic stenosis: results in 27 patients. J Thorac Cardiovase Surg 1976;17:380-7.

4. VBouhe POR, Neveax J-Y. Surgical management of diffuse subaortic stenosis: an integrated approach. Ann Thorac Surg 1991;52:654-62.

5. Lillehei CW, Levy MJ. Transatrial exposure for correction of subaortic stenosis: a new approach. JAMA 1963;186:8.

\title{
A NONNARROWING TECHNIQUE FOR IMPLANTATION OF THE DURAN FLEXIBLE RING
}

\author{
Jose M. Bernal, MD, and Jose M. Revuelta, MD, Santander, Spain
}

Prosthetic ring annuloplasty is a common procedure in both mitral and tricuspid valve repairs. The question of the optimum form of annuloplasty ring, however, whether rigid, semirigid, or entirely flexible, is still controversial. Although in a recent clinical study Okada and associates ${ }^{1}$ showed that flexible rings perform better under exercise conditions, the narrowing effect of the Duran flexible ring has been considered a disadvantage in comparison with

From the Department of Cardiovascular Surgery, Hospital Universitario Valdecilla, Universidad de Cantabria, Santander, Spain.

Received for publication Sept. 5, 1995; accepted for publication Sept. 19, 1995.

J Thorac Cardiovase Surg 1996;112:196-7

Copyright (C) 1996 by Mosby-Year Book, Inc.

$0022-5223 / 96 \$ 5.00+0 \quad \mathbf{1 2 / 5 4 / 6 9 3 3 8}$ remodeling annuloplasty with the rigid Carpentier ring. ${ }^{2}$ This report describes a nonnarrowing technique for Duran flexible ring annuloplasty.

Technique. At operation, the left atrium is entered just posterior to the interatrial groove and anterior to the pulmonary veins. The mitral valve is examined, and traction in the middle portion of the free edge of the anterior leaflet allows visualization of the trigones. An appropriately sized ring is selected according to the intertrigonal distance. Two 3-0 polypropylene double-armed sutures are placed in both trigones, and an additional suture is placed in the middle part of the posterior anulus. Stitches in the trigones are placed through the two ring markers (Fig. 1, Step 1). A running 3-0 polypropylene suture is used to seat the flexible ring along the intertrigonal area. The stay suture in the middle part of the posterior anulus is used as a key reference for reduction of the dilated 